\title{
Valores Pessoais, Vínculos com a Carreira e Comprometimento Organizacional
}

\author{
Mauro Oliveira Magalhães" \\ Universidade Federal da Bahia, Salvador, Brasil
}

\begin{abstract}
RESUMO
Foram investigadas as relações entre valores pessoais e vínculos do indivíduo com a carreira e com a organização de trabalho. Uma amostra de 209 trabalhadores, 116 homens e 93 mulheres, de diversos segmentos do setor terciário, responderam a medidas de comprometimento organizacional afetivo, comprometimento e entrincheiramento na carreira, e o Inventário de Valores de Schwartz. Análises de regressão revelaram que valores individualistas foram preditores do comprometimento com a carreira e valores coletivistas foram preditores do vínculo organizacional. Foram preditores positivos de entrincheiramento o poder e a tradição, e preditores negativos a autodeterminação e a benevolência. Os dados sugerem que diferentes focos e bases do vínculo indivíduo-trabalho estão associados a diferentes prioridades axiológicas.
\end{abstract}

Palavras-chave: valores; comprometimento organizacional; atitudes do empregado.

\section{ABSTRACT \\ Personal Values, Career Attachments and Organizational Commitment}

Relations between personal values, career attachments and organizational commitment were investigated. A sample of 209 workers, 116 men and 93 women, employed in diverse segments of the tertiary sector, answered measures of organizational commitment, career commitment and entrenchment, and Schwartz Value Inventory. Regression analysis revealed that individualist values were predictors of career commitment and collectivist values were predictors of organizational commitment. Power and tradition were positive predictors of career entrenchment and selfdetermination and benevolence were negative predictors. The data suggests that different foci and basis of individual-work attachments are associated with different axiological priorities.

Keywords: values; organizational commitment; employee attitudes.

Nos últimos anos observa-se o crescimento das pesquisas sobre as fontes disposicionais das atitudes relacionadas ao trabalho, e entre estas o impacto dos valores pessoais sobre o comprometimento no trabalho (Cohen \& Shamai, 2010). As novas relações de emprego, marcadas por incertezas e instabilidade, resultaram na fragilização dos vínculos entre trabalhadores e organizações. O enfraquecimento destes vínculos, aliado ao culto a autonomia da carreira individual, trouxe desafios importantes à possibilidade de articulação entre interesses individuais e organizacionais. No contexto do papel de trabalho, a compatibilidade entre o projeto de carreira individual e as metas organizacionais é um estado desejável para todos os envolvidos nestas relações. Os valores pessoais revelam a disposição do indivíduo para atender a interes- ses coletivos e/ou individuais. Neste sentido, as motivações de valor podem ser uma perspectiva de entendimento das inclinações individuais para um maior vinculo com a carreira ou com a organização, sendo esta última considerada uma entidade representante de interesses coletivos. No Brasil, pesquisas anteriores investigaram as relações entre valores pessoais, ou prioridades axiológicas, e o comprometimento organizacional (Tamayo et al., 2001; Fernandes \& Ferreira, 2009). As relações entre valores pessoais e vínculos com a carreira foram pouco exploradas (Cohen, 2009). Esta pesquisa investigou a influência dos valores pessoais sobre os vínculos do indivíduo com a sua carreira profissional e com a sua organização empregadora em trabalhadores da iniciativa privada. Sobre este último aspecto, acredita-se que esses trabalhadores

Endereço para correspondência: Mauro Oliveira Magalhães - mauro.m@ terra.com.br 
estejam inseridos num contexto de incertezas sobre a sua empregabilidade futura diante da nova complexidade do mundo do trabalho. A seguir será apresentado um breve histórico recente das pesquisas sobre vínculos com a carreira e com a organização, sobre as relações entre valores e comprometimento no trabalho, para então delimitar os objetivos específicos do presente estudo.

\section{O comprometimento organizacional}

A pesquisa sobre comprometimento organizacional possui um histórico caracterizado pela diversidade de conceitos e medidas. Nos trabalhos seminais de Mowday et al. (Mowday, Steers, \& Porter, 1979), o comprometimento organizacional foi definido como a aceitação dos valores e objetivos da organização, associada a disposição para permanecer e dedicar-se ao benefício da mesma. A seguir, este campo de pesquisa se diversificou nos desdobramentos associados aos denominados focos e bases do comprometimento. A diferenciação entre focos refere-se ao fato que os diferentes elementos que constituem a vida de trabalho podem ser objeto de comprometimento, tais como a organização, a carreira, o sindicato, a equipe de colegas, entre outros. E a diferenciação entre as bases refere-se ao reconhecimento de que diferentes processos psicológicos podem estar subjacentes ao vínculo com a organização (Cooper-Hakim \& Viswesvaram, 2005).

A pesquisa sobre as bases do comprometimento organizacional é representada no modelo tridimensional de Meyer e Allen (1991), que inclui as três principais tradições de pesquisa sobre o tema: (a) afetiva/atitudinal: enfatiza a identificação com objetivos e valores da organização; (b) instrumental: o comprometimento resulta do balanço de custos e benefícios associados à permanência na organização; e (c) normativa: o comprometimento resulta de pressões internalizadas de conformidade aos objetivos da organização. Assim, o vínculo afetivo apoia-se no orgulho, no sentimento de pertencer e no assumir os problemas da organização. O comprometimento instrumental resulta da percepção de altos custos e perdas associadas ao abandono da organização e da crença de não se ter alternativas de emprego. E o comprometimento normativo resulta de imperativos morais de retribuição e lealdade à organização.

Após três décadas e numerosos estudos, a tendência atual é definir o comprometimento com a organização em termos unidimensionais, com opção pela base afetiva, caracterizada como uma vinculação por processos de identificação e internalização dos valores organizacionais, e o consequente desejo de contribuir para a realização destes valores (Rodrigues \& Bastos, 2010). Rodrigues e Bastos (2010) esclarecem que "o 'ser comprometido' que, até o final do século $\mathrm{XX}$, estava associado à ideia de permanência, passa a incorporar a noção de contribuição ativa para a organização". (p. 131) E as definições de comprometimento no trabalho têm sofrido reformulações a fim de incorporar dimensões relativas à efetiva identificação e investimento do indivíduo nos diversos componentes da sua vida de trabalho, seja a carreira ou a organização.

\section{O comprometimento com a carreira}

Riveros e Tsai (2011) consideram que uma força motivacional direcionada ao alcance de metas em determinado papel de carreira é o denominador comum das definições correntes de comprometimento com a carreira.

Em relação à mensuração do construto, Carson e Bedeian (1994) propuseram uma medida de três componentes, a partir da base conceitual de London (1983). Estes componentes são a identificação com o trabalho (identidade), a autoavaliação e o estabelecimento de metas e planos (planejamento de carreira), e a capacidade de lidar com adversidades (resiliência). Esta concepção aproxima-se das definições atuais do comprometimento, com significado de identificação e envolvimento ativo na conquista de objetivos de carreira (ou da organização, no caso do comprometimento organizacional). A versão brasileira da escala de comprometimento de carreira de Carson e Bedeian (1994) revelou boas qualidades psicométricas e atendeu a critérios de validade de constructo (Magalhães \& Gomes, 2007; Magalhães, 2008; Rowe \& Bastos, 2011).

Entre as pesquisas sobre as relações entre diferentes focos de comprometimento destacam-se as investigações sobre o possível conflito entre os vínculos com a carreira e com a organização. De um modo geral, se aceita a hipótese que a compatibilidade entre valores pessoais e organizacionais seja responsável pelas correlações positivas ou negativas entre estas medidas de vínculo (Cooper-Hakim \& Viswesvaram, 2005). Por outro lado, a clássica diferenciação de Gouldner (1957) entre trabalhadores cosmopolitas e localistas ainda é lembrada por pesquisadores da área (Fuller, Hester, Barnett, Frey, \& Reylea, 2006). Os cosmopolitas teriam baixa lealdade à organização e alto comprometimento com a profissão, pois são indivíduos mais preocupados com a obtenção de status e 
reconhecimento em suas comunidades profissionais específicas. Já os localistas teriam alto comprometimento com a organização e baixo com a profissão.

\section{O entrincheiramento na carreira}

Sabe-se que a crise do emprego demove muitos trabalhadores de assumir os riscos inerentes à busca de novas oportunidades ou opções de carreira, uma vez empregados e supostamente estabilizados em suas carreiras. A situação de trabalhadores que permanecem atrelados a uma área de trabalho ou emprego por receio de perdas materiais, custos emocionais e/ou por dificuldades percebidas para encontrar alternativas de trabalho foi denominada de entrincheiramento (Carson, Carson, \& Bedeian, 1995). O indivíduo entrincheirado encontra-se numa posição fixa e defensiva, como sugere o significado da palavra. Este processo tem sido investigado em relação aos focos carreira (Magalhães \& Gomes, 2007; Rowe \& Bastos, 2011) e organização (Carvalho, Alves, Peixoto, \& Bastos, 2011) como a expressão de uma base psicológica instrumental de vínculo.

De acordo com Carson, Carson e Bedeian (1995), o entrincheiramento resulta de três categorias de fatores: investimentos na carreira, custos emocionais e falta de alternativas de carreira. Os investimentos incluem o tempo, dinheiro e esforço necessários à obtenção de habilidades específicas e credenciais educacionais, assim como o salário, posição e outros aspectos. $\mathrm{O}$ acúmulo de investimentos numa linha de carreira (tempo, treinamentos, relações sociais) gera recompensas materiais e sociais, e resulta no desejo de preservar estes benefícios e evitar os custos emocionais de uma mudança nesta situação. E a falta de alternativas refere-se à percepção da restrição de oportunidades de crescimento e/ou mudança na carreira. Carson, Carson e Bedeian (1995) desenvolveram uma medida de entrincheiramento na carreira com a estrutura tridimensional descrita acima. A versão brasileira desta medida apresentou qualidades psicométricas adequadas (Magalhães, 2008).

\section{Os tipos motivacionais de valores}

Para Schwartz (1992), os valores, ou prioridades axiológicas, são metas transituacionais, que variam em importância e servem como princípios na vida de uma pessoa ou coletividade. Essas metas podem ser descritas como respostas a três demandas inerentes a vida humana: necessidades biológicas, de interação social e de bom funcionamento e sobrevivência da coletividade. Destas três necessidades universais ori- ginam-se os dez tipos motivacionais de valor (TMVs), descritos por Schwartz (1992) e listados a seguir.

a) Hedonismo: prazer e gratificação sensual para si mesmo;

b) Realização: sucesso pessoal reconhecido através da demonstração de competência em acordo com padrões sociais;

c) Poder social: controle sobre pessoas e recursos, visando prestígio e status social;

d) Autodeterminação: independência de pensamento e ação, definição autônoma de metas; Estimulação: excitação, novidade, mudanças e desafios na vida;

e) Conformidade: controle de impulsos e ações que podem violar normas ou expectativas sociais, ou prejudicar os outros;

f) Tradição: respeito, comprometimento e aceitação dos ideais e costumes que a cultura tradicional ou religião determina;

g) Benevolência: promoção do bem-estar das pessoas com as quais se tem contato frequente, altruísmo;

h) Segurança: integridade social, estabilidade da sociedade, dos relacionamentos e de si mesmo;

i) Universalismo: tolerância, compreensão e promoção do bem-estar de todos e da natureza.

Os dez TMVs ainda podem ser agrupados em quatro categorias mais abrangentes, através de duas dimensões bipolares. A primeira, abertura à mudança versus conservação, contrasta motivações para independência, busca por mudanças e desafios (TMVs estimulação e autodeterminação) com motivações de preservação do estabelecido e da segurança que este gera no relacionamento com os outros e com as instituições (TMVs segurança, conformidade e tradição). A segunda dimensão, autopromoção versus autotranscendência, polariza valores relativos ao poder, realização e hedonismo, em contraposição a valores de universalismo e benevolência. Deste modo, contrasta motivações para defender interesses próprios mesmo com o prejuízo alheio, por oposição ao desejo de transcender preocupações pessoais e promover o bemestar social e da natureza (Tamayo \& Schwartz, 1993).

Os cinco tipos de valores que expressam necessidades individuais são autodeterminação, estimulação, hedonismo, realização e poder social. Os três tipos de valores que expressam primariamente demandas cole- 
tivas são benevolência, tradição e conformidade. Por fim, segurança e universalismo expressam necessidades tanto individuais quanto coletivas. O Inventário de valores de Schwartz (1992) foi traduzido e validado no Brasil por Tamayo e Schwartz (1993). A versão brasileira inclui, além dos 57 itens da versão internacional, quatro valores característicos da cultura brasileira (Tamayo, 1994). Este modelo foi testado em diversas culturas, revelando sua consistência e validade (Tamayo \& Schwartz, 1993). Pesquisas brasileiras tem revelado sua utilidade no entendimento do comportamento no trabalho (Tamayo \& Porto, 2005).

\section{Valores pessoais e comprometimento no trabalho}

De acordo com Cohen (2009), embora muitos estudos tenham sido realizados sobre os vínculos individuo-trabalho, a investigação da relação entre valores individuais e os diversos aspectos do comprometimento no trabalho ainda é insuficiente. Pesquisas mostraram que os valores são preditores ou moderadores de processos associados ao comprometimento organizacional, à satisfação no emprego e ao desempenho no trabalho (e.g., Glazer, Daniel, \& Short, 2004). No entanto, a maioria tem abordado os valores de trabalho, mais do que valores pessoais gerais.

É razoável supor que o comportamento no trabalho dependa mais dos valores relacionados a este domínio específico de atividade do que a valores gerais de vida. Por outro lado, alguns autores defendem a importância dos valores gerais como preditores de comprometimento no trabalho (Cohen, 2009). Entre os poucos estudos que examinaram esta relação, Clugston, Howell, and Dorfman (2000) utilizaram o modelo de dimensões culturais de valor de Hofstede (1980), avaliando-as em nível individual. Os autores encontraram relações entre distancia do poder e comprometimento organizacional normativo, entre evitação de incerteza e comprometimento de continuação (ou de base instrumental) com a organização, o supervisor e grupo de trabalho; e entre coletivismo e comprometimento de bases afetiva, normativa e de continuação com o grupo de trabalho. E a pesquisa de Cohen (2007) observou que os valores individuais agregam explicação ao comprometimento no trabalho para além do pertencimento a determinados grupos culturais. Por outro lado, as pesquisas com base nas ideias de Hofstede (1980) têm recebido críticas relacionadas ao seu foco estreito na dimensão individualismo versus coletivismo (Gelfand, Erez, \& Aycan, 2007).

A teoria dos valores humanos de Schwartz (1992) tem recebido a atenção crescente de pesquisadores interessados nas relações entre valores e atitudes e comportamentos no trabalho. A pesquisa de Glazer et al. (2004) observou relações negativas entre valores de conservação e comprometimento de base instrumental e entre abertura a mudança e comprometimento afetivo com a organização. Fischer e Smith (2006) não encontraram relações diretas entre valores e comprometimento organizacional de base afetiva. Eles concluíram que outras formas de comprometimento devem ser examinadas para clarificar a relação entre valores pessoais e vínculos indivíduo-trabalho.

Na pesquisa de Cohen (2009), o valor benevolência mostrou ser relevante para o desenvolvimento de comprometimento no local de trabalho, associando-se positivamente com vínculos com a organização, com a ocupação e com a equipe de trabalho. $\mathrm{O}$ autor sugeriu que trabalhadores com escores elevados em benevolência desenvolvem laços mais fortes com seus colegas de trabalho. Neste sentido, pesquisas anteriores encontraram fortes associações entre o valor individual de coletivismo e comprometimento no trabalho (Clugston et al., 2000; Cohen, 2007). O comportamento gregário e sociável também se mostrou importante para o comprometimento organizacional na pesquisa de Erdheim, Wang e Zickar (2006). Neste estudo, o traço de extroversão correlacionou com as três bases do comprometimento, positivamente com a base afetiva e normativa, e negativamente com a instrumental. Estes achados sugerem que o comprometimento deriva mais de sentimentos de conexão e comunidade entre colegas do que de outras características ou contextos do papel de trabalho (Cohen, 2009). E, tendo em vista a extensa implantação de equipes e outras formas de articulação cooperativa no mundo do trabalho, valores pessoais favoráveis a comportamentos afiliativos podem adquirir relevância ainda maior para a relação entre indivíduo e organização. Sendo assim, Cohen (2009) recomendou atenção ao papel do valor benevolência na formação de vínculos no trabalho.

Entre os resultados de Cohen (2009) destaca-se também a relação negativa entre o valor estimulação e o comprometimento organizacional. Sabendo-se que o valor estimulação encontra-se no polo de abertura à mudança, o autor interpretou este resultado sugerindo que o comprometimento organizacional possa também significar a satisfação com o status quo e, portanto, a rejeição a mudanças. Cohen e Shamai (2010) investigaram a relação entre valores individuais, bem-estar psicológico e comprometimento organizacional em oficiais de polícia. As análises de regressão mostraram relação positiva entre bem-estar e os valores de bene- 
volência, autodeterminação e realização; e uma relação negativa entre bem-estar e os valores de poder e tradição. Os autores surpreenderam-se com a associação negativa de comprometimento organizacional com o valor realização e positiva com o valor poder, o inverso das relações destes valores com o bem-estar psicológico. Sendo assim, os resultados indicaram correlação negativa entre comprometimento e bemestar. Estes resultados sugerem ser fortemente influenciados pelo tipo específico de organização e profissionais estudados.

No Brasil, Tamayo et al.(2001) relataram que tradição, poder e universalismo foram preditores positivos e estimulação foi preditor negativo do comprometimento organizacional numa amostra de 200 servidores públicos. Observa-se que o resultado referente ao valor estimulação concorda com Cohen (2009) e referente ao valor poder foi corroborado por Cohen e Shamai (2010). Ao verificar a influência dos quatro fatores de ordem superior, Tamayo e colaboradores (2001) observaram que somente conservação foi antecedente do comprometimento organizacional. Portanto, concluíram que o vínculo com a organização "parece atender motivações de conservação do status quo, de procura do bem-estar coletivo e de obtenção de status social, de prestígio e de controle de pessoas e recursos", sendo desfavorecido quando o indivíduo valoriza a busca de novidades e desafios (p. 33). Os autores salientaram a importância de se realizar novas pesquisas em empresas privadas. Neste sentido, Cohen (2009), considerando as características de sua amostra de bancários veteranos, também sugeriu investigar estas relações em contextos laborais mais instáveis e que requeiram maior proatividade dos empregados.

$\mathrm{Na}$ amostra heterogênea de Fernandes e Ferreira (2009), conservação foi o único preditor significativo das três bases de comprometimento organizacional. As autoras também investigaram a influência da percepção de valores organizacionais, e concluíram que "as pessoas que dão maior importância à conservação e as que percebem a sua organização como mais conservadora [...] são as que se sentem mais vinculadas afetivamente à mesma” (p. 347).

O presente estudo dá seguimento a esta agenda de pesquisa e examina as relações entre valores pessoais, utilizando o modelo de Schwartz (1992), e vínculos do trabalhador com a organização e com a carreira, a saber: comprometimento organizacional afetivo, comprometimento com a carreira e entrincheiramento na carreira. Não há registro de estudos brasileiros sobre a relação entre valores e vínculos com a carreira. A comparação entre os preditores axiológicos dos vínculos com a carreira e com a organização pode ser útil para investigar se ocorrem ou não antecedentes comuns, e agregar elementos à discussão sobre a maior ou menor compatibilidade entre estes vínculos. A revisão da literatura sugere que o comprometimento com a carreira esteja relacionado a valores mais individualistas e o vínculo afetivo com a organização, tal como em estudos anteriores (Tamayo et al. 2001; Fernandes \& Ferreira, 2009), esteja associado a valores coletivistas. O entrincheiramento na carreira é um tema recente com implicações importantes para a gestão de pessoas e que requer melhor caracterização. Por fim, seguindo a sugestão de Tamayo et al. (2001), a população escolhida para esta pesquisa foi de trabalhadores da iniciativa privada, inseridos num mercado de trabalho dinâmico e instável, pressionados por necessidades de manter sua empregabilidade num ambiente de incertezas.

\section{MÉTODO}

\section{Participantes}

Participaram desta pesquisa 209 trabalhadores empregados em organizações privadas de diversos ramos de atividade do setor terciário, 116 homens e $93 \mathrm{mu}-$ lheres, com idades entre 25 e 54 anos $(\mathrm{M}=35,67$; DP $=6,87$ ), com mais de 1 ano de vínculo com a organização em que trabalham $(\mathrm{M}=5,97 ; \mathrm{DP}=4,77)$ e mais de 5 anos de carreira profissional $(\mathrm{M}=12,15$; $\mathrm{DP}=$ $5,89)$. Em termos de escolaridade, 40 possuíam ensino médio completo, 109 estavam cursando graduação superior, 33 possuíam ensino superior completo e 27 eram pós-graduados.

\section{Instrumentos}

Os participantes informaram dados demográficos e responderam a medidas de valores pessoais e vínculos com a organização. O Inventário de Valores de Schwartz (1992), traduzido e validado para amostras brasileiras por Tamayo \& Schwartz (1993), inclui, além dos 57 itens originais, quatro valores característicos da cultura brasileira (Tamayo, 1994), totalizando 61 itens que avaliam os dez TMVs descritos na introdução. Na amostra investigada, estas escalas apresentaram alfas de Cronbach entre 0,62 e 0,75.

O comprometimento com a carreira foi avaliado pela versão brasileira da Escala de Comprometimento com a Carreira (ECC) de Carson e Bedeian (1994), com 12 itens e três fatores: identidade, planejamento e 
resiliência. Neste estudo a escala e suas dimensões apresentaram alfas de Cronbach entre 0,76 e 0,86. O entrincheiramento foi avaliado pela versão brasileira da Escala de Entrincheiramento na Carreira (EEC) de Carson, Carson e Bedeian (1995), com 12 itens e três fatores: investimentos de carreira, custos emocionais e falta de alternativas. Neste estudo a escala e suas dimensões apresentaram alfas de Cronbach entre $0,82 \mathrm{e}$ 0,87 . O comprometimento organizacional foi mensurado pela escala de Mowday, Steers e Porter (1979), traduzida e adaptada para o contexto brasileiro por Borges-Andrade, Afanasieff e Silva (1989), que apresentou consistência interna (alfa de Cronbach) 0,87.

\section{Procedimentos}

A coleta de dados foi coletiva e realizada no local de trabalho dos participantes, com o prévio consentimento dos mesmos e das autoridades responsáveis. Os escores brutos do Inventário de Valores de Schwartz (1992) foram transformados de acordo com recomendações do autor (Schwartz, 2005, 2009), a fim de controlar diferenças individuais no uso das escalas de TMVs. Os escores foram corrigidos considerando o desvio em relação a media geral de cada indivíduo.

Os dados foram analisados por regressão múltipla (método stepwise), tendo como variáveis independentes os tipos motivacionais de valores e como variáveis dependentes as medidas de vínculo com a carreira e com a organização. As análises foram repetidas tendo como variáveis independentes as dimensões de segunda ordem (abertura, autopromoção, conservação e autotranscendência), tempo de carreira e na organização, idade e escolaridade. Foram anteriormente exa- minados os pressupostos da regressão múltipla. Os indicadores de normalidade, homogeneidade de variâncias, linearidade e singularidade foram considerados satisfatórios, atendendo as recomendações da literatura (Tabachnick \& Fidell, 1996). O exame de casos influentes identificou apenas um caso a ser descartado. Análises de correlação bivariada foram realizadas entre os preditores a fim de examinar aspectos de multicolinearidade. As correlações entre as variáveis independentes (TMVs) foram aceitáveis, apoiando a premissa de não colinearidade. Posteriormente, os indicadores de tolerância e FIV (Fator de Inflação de Variância) permitiram assumir este pressuposto. No entanto, a fim de atender às recomendações do autor (Schwartz, 2009), que asseveram a inadequação da inclusão de todos os dez TMVs como preditores em uma equação de regressão, estas análises foram precedidas pelo exame das correlações bivariadas entre as variáveis independentes e a variável critério em cada caso. Foram excluídas das análises de regressão as variáveis independentes que não mostraram correlação bivariada significativa com a variável critério. Deste modo, todas as análises foram realizadas com menos de oito TMVs como variáveis independentes.

\section{RESULTADOS}

Os resultados das análises de regressão (método stepwise) tendo como variáveis dependentes as medidas de vínculo com a carreira e a organização e como variáveis independentes os tipos motivacionais de valores estão apresentados na Tabela 1.

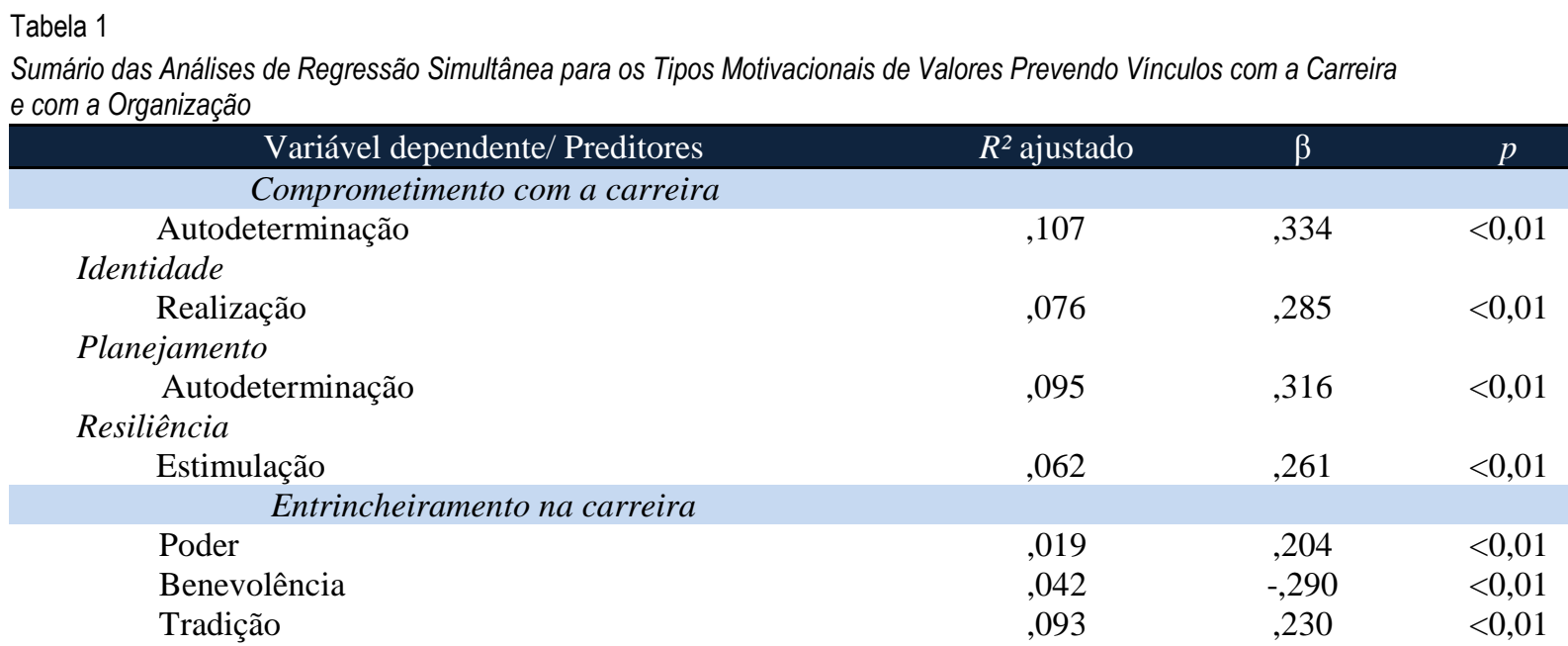


Falta de alternativas

Benevolência

$\begin{array}{lccc} & , 029 & -, 299 & <0,01 \\ & , 097 & , 369 & <0,01 \\ & , 119 & -, 186 & <0,01 \\ & , 073 & , 341 & <0,01 \\ & , 116 & -, 272 & <0,01 \\ & , 026 & , 178 & <0,05 \\ & , 078 & , 290 & <0,05\end{array}$

Conformidade

Tradição

Autodeterminação

Investimentos de carreira

Poder

Benevolência

Custos emocionais

Tradição Comprometimento organizacional
Os resultados das análises de regressão (método segunda ordem, tempo de carreira e na organização, stepwise) tendo como variáveis dependentes as mediidade e escolaridade estão apresentados na Tabela 2. das de vínculo com a carreira e a organização e como variáveis independentes as dimensões axiológicas de

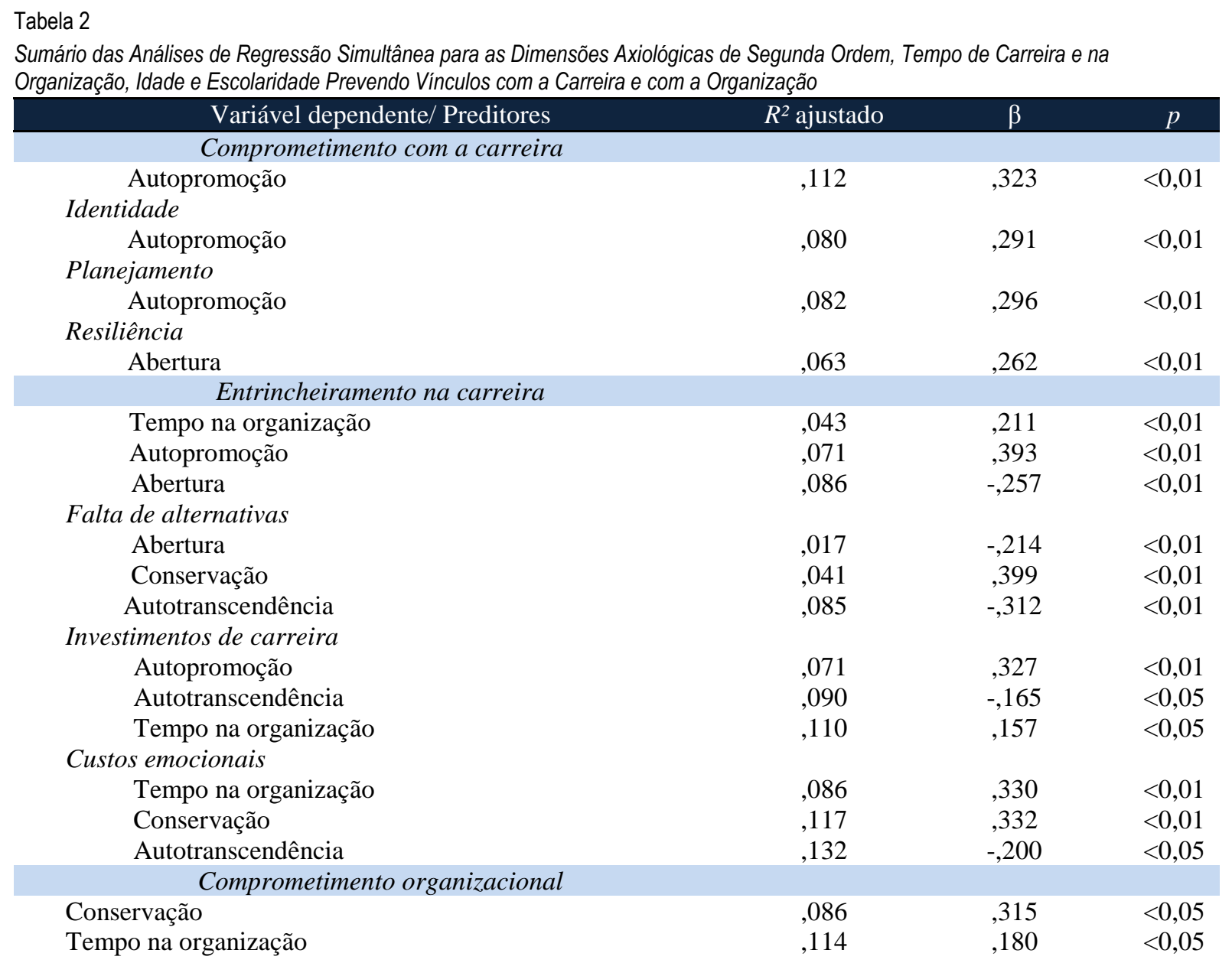

\section{DISCUSSÃO}

Entre os preditores do comprometimento com a carreira destacou-se o TMV autodeterminação, que foi o único preditor do escore total, explicando $10,7 \%$ da variância e também explicou 9,5\% da variância de planejamento de carreira. O planejamento implica pensar o próprio futuro, definir metas e planos de carreira, que são comportamentos associados à valori- 
zação da autonomia e da criatividade inerentes à autodeterminação. Este TMV, inserido na dimensão mais ampla de abertura, manifesta a motivação individual para atender aos próprios interesses, o que demanda planejar a vida e a carreira.

O TMV realização foi o único preditor da identidade de carreira. Entende-se que este valor corresponde à valorização do sucesso pessoal, alcançado através da demonstração de competências, corroborando o conceito de identidade de London (1983).

Sobre o componente resiliência, o TMV estimulação foi preditor positivo. A resiliência refere-se à superação de circunstâncias problemáticas que atinjam a carreira, o que inclui a aceitação de desafios e riscos. Ora, o TMV estimulação refere-se ao desejo de enfrentar desafios e de sentir-se assim estimulado, motivações favoráveis à resiliência de carreira.

As variáveis idade, escolaridade, tempo de carreira e tempo na organização não foram preditores significativos de variáveis de comprometimento com a carreira. Este resultado sugere que o vínculo com a carreira depende mais de fatores disposicionais e seja uma atitude mais independente do indivíduo em relação ao papel de trabalho.

Sobre os preditores de entrincheiramento, observa-se, por um lado, a valorização de motivações de autopromoção (poder) e conservação (tradição) e, por outro, o peso negativo de motivações de abertura (autodeterminação) e, principalmente, de autotranscendência (benevolência). Portanto, os resultados sugerem que o entrincheiramento resulta de uma combinação particular do desejo de conservar a posse e/ou o controle alcançado sobre consequentes materiais e sociais valorizados da posição de trabalho atual. O tempo na organização, um preditor que se mostrou igualmente importante, vem reforçar o acúmulo de investimentos e os custos associados a possível perda de conquistas financeiras e de status no emprego atual. Além disto, o peso negativo de valores pertencentes à polaridade abertura pode significar a recusa a explorar novas perspectivas de carreira.

Entre os preditores de entrincheiramento destaca-se o TMV benevolência com peso negativo para predição dos escores totais e dos componentes falta de alternativas e investimentos de carreira. Sendo a benevolência um tipo de motivação de valor relacionada à promoção do bem-estar de outras pessoas, expressando interesses coletivos, pode-se supor que a carência destas motivações resulte em dificuldades para conquistar uma posição favorável nas redes sociais no contexto de trabalho e também fora dele. Na pesquisa de Cohen (2009), o valor benevolência se mostrou relevante para a formação de vínculos afetivos no local de trabalho. Portanto, sabendo-se da importância de redes de apoio social para a exploração de alternativas profissionais, oportunidades de emprego e para o planejamento da carreira (Savickas, Briddick, \& Watkins, 2002), entende-se a associação negativa entre benevolência e os escores de entrincheiramento e a falta de alternativas de carreira.

O TMV benevolência também foi preditor negativo do desejo de evitar a perda de investimentos de carreira. Sobre este resultado, acredita-se que a aceitação dessas perdas possa ser facilitada por valores que incluam a tolerância a sacrifícios pessoais e motivações de autotranscendência, como é o caso da benevolência. Além disto, a falta de apoio social pra o enfrentamento das perdas inerentes a transições de carreira pode estar relacionada à falta do TMV benevolência.

Os resultados indicam que as motivações para preservar investimentos realizados e evitar os custos emocionais associados a transições de carreira podem ser expressões dos TMVs poder e tradição. O indivíduo que prioriza motivações de poder dificilmente irá abdicar de conquistas materiais e de status a fim de experimentar outras possibilidades de vida. O TMV tradição pode vir a reforçar esta motivação, uma vez que a aceitação dos ideais e costumes da sociedade reforça a preocupação em não perder posições valorizadas socialmente.

Na pesquisa de Kamia e Porto (2011), o TMV estimulação apresentou a relação mais forte com o comportamento proativo, seguido do tipo antagônico tradição, que se relacionou negativamente. Portanto, a presença importante do TMV tradição como preditor dos escores totais e parciais de entrincheiramento (falta de alternativas e custos emocionais) e o peso negativo de valores de abertura (estimulação e autodeterminação) reforça a caracterização do entrincheiramento como uma condição em que há carência de proatividade. Por fim, a presença do TMV autodeterminação como preditor negativo de falta de alternativas de carreira corresponde a expectativas teóricas, uma vez que a valorização da independência e da liberdade de escolha não favorece uma percepção de imobilidade na carreira, característica do entrincheiramento.

Em termos das dimensões axiológicas de segunda ordem, os antecedentes do comprometimento com a carreira estão associados às dimensões de autopromo- 
ção e abertura, e os antecedentes do entrincheiramento se caracterizam por uma relação negativa com abertura e autotranscendência e positiva com autopromoção e conservação. Sendo assim, ambos os tipos de vínculo com a carreira expressam motivações de autopromoção. Porém, o comprometimento inclui a abertura a novas possibilidades de desenvolvimento profissional, desafios e aprendizados. E o entrincheiramento revela a preocupação por conservar posições conquistadas e um menor interesse no bem-estar de outras pessoas.

Noutra perspectiva, observa-se que os preditores do comprometimento com a carreira e de suas dimensões correspondem a três entre os cinco TMVs que expressam interesses primariamente individuais. Por outro lado, os preditores do entrincheiramento na carreira incluem TMVs relacionados a interesses individuais e coletivos. No entanto, observa-se, em relação ao entrincheiramento, que a suposta valorização de interesses coletivos se apresenta de modo a atender necessidades individuais, uma vez que se valoriza a conservação de uma condição considerada favorável pelo indivíduo.

Cohen e Shamai (2010) observaram relação positiva entre bem-estar e valores de benevolência, autodeterminação e realização; e uma relação negativa entre bem-estar e valores de poder e tradição. A transposição destes resultados para os dados da presente pesquisa sugere uma associação positiva entre comprometimento com a carreira e bem-estar e uma redução do bem-estar psicológico em processos de entrincheiramento. Neste sentido, prejuízos ao bem-estar por consequência do entrincheiramento na carreira foram citados em estudos anteriores (Carson, Carson, \& Bedeian, 1995; Carson \& Carson, 1997) e, considerando os resultados do presente estudo, podem estar associados a uma priorização estrita dos valores poder e tradição. Entende-se que estes TMVs, em si mesmos, não são a razão de mal-estar psicológico. Por outro lado, no caso do entrincheiramento, a combinação destas prioridades com o rechaço a dimensões de abertura e autotranscendência pode significar um desequilíbrio prejudicial ao bem-estar.

Sobre o comprometimento organizacional afetivo, na primeira análise de regressão, conformidade foi seu único preditor significativo entre os TMVs, e explicou $7,8 \%$ da variância. Na segunda análise, em termos das dimensões de segunda ordem, conservação explicou $8,6 \%$ da variância. E o tempo na organização agregou mais $2,8 \%$ a esta explicação.
A conformidade é um dos TMVs que compõem a dimensão de conservação e refere-se ao controle de impulsos e ações que possam transgredir regras, desapontar expectativas ou prejudicar outras pessoas. A dimensão conservação inclui os TMVs tradição, conformidade e segurança, um conjunto de motivações voltadas para a preservação do estabelecido e da segurança que este gera. Portanto, na amostra investigada, o vinculo afetivo com a organização se mostrou associado a um conjunto específico de motivações de valor, com ênfase importante na conformidade. Este resultado difere em parte dos achados de Tamayo et al. (2001) em uma amostra de funcionários públicos, onde tradição, poder e universalismo foram preditores positivos e estimulação foi um preditor negativo do comprometimento organizacional. Esta diferença pode ser explicada tendo em vista que a amostra do presente estudo é formada por trabalhadores da iniciativa privada, inseridos num mercado de trabalho instável e incerto, sem quaisquer expectativas de estabilidade no emprego. Nestas condições de trabalho menos previsíveis e controláveis, o comprometimento com a organização pode ser o resultado mais estrito de motivações de conformidade, sem incluir aspirações de controle sobre pessoas e recursos (TMV poder) ou o desejo de promover o bem-estar de outros (TMV universalismo).

Por outro lado, quanto ao poder preditivo dos quatro fatores de ordem superior, assim como no presente estudo, na amostra de Tamayo et al. (2001) somente conservação surgiu como antecedente do comprometimento organizacional. Este resultado também corrobora a pesquisa mais recente de Fernandes e Ferreira (2009), onde a dimensão conservação foi o único preditor significativo de comprometimento organizacional afetivo quando incluídos os valores organizacionais no modelo. Portanto, até o momento, os estudos convergem para caracterizar os preditores axiológicos do comprometimento organizacional como relacionados à motivação de adequar-se a e preservar o status quo.

Assim como esperado, os dados confirmam a expectativa que o comprometimento com a carreira seja uma expressão de interesses primariamente individuais e que o comprometimento com a organização seja uma expressão de valores coletivistas. Isto não significa dizer que estes vínculos são incompatíveis, pois se acredita que todo ser humano possua, em proporções variáveis, motivações coletivistas e individualistas. No entanto, pode-se dizer que as oportunidades percebidas de expressão das motivações individualistas se encontram no foco carreira e das coletivistas no foco organização. 


\section{CONSIDERAÇÕES FINAIS}

Esta pesquisa permitiu uma primeira caracterização das motivações de valor associadas às bases afetiva e instrumental do vínculo com a carreira. $\mathrm{O}$ entrincheiramento, um vínculo de base instrumental, se mostrou influenciado por uma combinação de prioridades que sugere correspondência com sua definição conceitual e operacionalização em componentes de investimentos, custos e falta de alternativas de carreira. Em síntese, o entrincheiramento parece resultar do apego às conquistas materiais e sociais alcançadas (poder e tradição), da falta de independência e proatividade (abertura e autodeterminação com peso negativo) e da menor preocupação com o bem-estar de outras pessoas (benevolência com peso negativo). Salienta-se que esses últimos aspectos seriam úteis para a exploração de alternativas de carreira e para o enfrentamento dos desgastes e perdas inerentes a mudanças na carreira. Portanto, os dados apoiam a caracterização do entrincheiramento apresentada em estudos anteriores (Carson, Carson, \& Bedeian, 1995; Magalhães, 2008; Magalhães \& Gomes, 2007).

A citada diferença entre os preditores de comprometimento com a carreira e com a organização traz à tona a clássica polarização feita por Gouldner (1957) entre trabalhadores cosmopolitas e localistas, aqui transposta para o campo das prioridades de valor. No entanto, sugere-se que estudos posteriores investiguem se esta polarização se mantém ao levar-se em consideração a percepção de compatibilidade entre valores pessoais e organizacionais. Acredita-se que trabalhadores que percebam uma congruência entre seus valores pessoais e os organizacionais possam perceber o desenvolvimento de sua carreira em determinada organização como a expressão de interesses também coletivos. Por fim, os dados sugerem que diferentes focos e bases do vínculo indivíduo-trabalho estão associados a diferentes prioridades axiológicas, uma conclusão a ser replicada desde outras perspectivas.

\section{REFERÊNCIAS}

Borges-Andrade, J., Afanasieff, R., \& Silva, M. (1989). Mensuração de comprometimento organizacional em instituições públicas. In Sociedade Brasileira de Psicologia (Ed.), XIX Reunião Anual de Psicologia. Resumos (p. 236). Ribeirão Preto: SBP.

Carson, K. D., \& Bedeian, A. G. (1994). Career commitment: Construction of a measure and examination of its psychometric properties. Journal of Vocational Behavior, 44(3), 237-262.

Carson, K. D., Carson, P. P., \& Bedeian, A. G. (1995). Development and construct validation of a career entrenchment measure.
Journal of Occupational and Organizational Psychology, 68, 301-320.

Carson, K. D., \& Carson, P. P. (1997). Career entrenchment: a quiet march toward occupational death? Academy of Management Review, 11(1), 63-75.

Carvalho, P., Alves, F. J. O., Peixoto, A. L. A., \& Bastos, A. V. B. (2011). Comprometimento afetivo, de continuação e entrincheiramento organizacional: estabelecendo limites conceituais e empíricos. Revista de Psicologia: Teoria e Prática, 3, 127-141.

Clugston, M., Howell, J. P., \& Dorfman, P. W. (2000). Does cultural socialization predict multiple bases and foci of commitment? Journal of Management, 26, 5-30.

Cohen, A. (2009). A value based perspective on commitment in the workplace: An examination of Schwartz's basic human values theory among bank employees in Israel. International. Journal of Intercultural Relations, 33, 332-345.

Cohen, A., \& Shamai, O. (2010). The relationship between individual values, psychological well-being, and organizational commitment among Israeli police officers, Policing: An International Journal of Police Strategies \& Management, 33 (1), $30-51$.

Cooper-Hakim, A., \& Viswesvaran, C. (2005). The construct of work commitment: testing an integrative framework. Psychological Bulletin, 131(2), 241-259.

Gelfand, M. J., Erez, M., \& Aycan, Z. (2007). Cross-cultural organizational behavior. Annual Review of Psychology, 58, 479-514.

Glazer, S., Daniel, S. K., \& Short, K. M. (2004). A study of relationship between organizational commitment and human values in four countries. Human Relations, 57, 323-345.

Gouldner, A.W. (1957). Cosmopolitans and locals: toward an analysis of latent social roles. Administrative Science Quarterly, 2, 281-306.

Goulet, L., \& Singh, P. (2002). Career commitment: a reexamination and an extension. Journal of Vocational Behavior, 61(1), 73-91.

Fischer, R., \& Smith, P. B. (2006). Who cares about justice? The moderating effect of values on the link between organizational justice and work behaviour. Applied Psychology: An International Review, 55, 541-562.

Cohen, A. (2007). An examination of the relationship between commitments and culture among five cultural groups of Israeli teachers. Journal of Cross-Cultural Psychology, 38, 34-49.

Fuller, J. B., Hester, K., Barnett, T., Frey, L., \& Relyea, C. (2006). Perceived organizational support and perceived external prestige: predicting organizational attachment. The Journal of Social Psychology, 146(3), 327-347.

Hofstede, G. (1980). Cultures consequences: International differences in work related values. Beverly Hills: Sage.

Kamia, M., \& Porto, J. (2011). Comportamento proativo nas organizações: o efeito dos valores pessoais. Psicologia: Ciência e Profissão, 31(3), 456-467. 
London, M. (1983). Toward a theory of career motivation. Academy of Management Review, 8(4), 620-630.

Magalhães, M. O. (2008). Propriedades psicométricas da versão brasileira da escala de entrincheiramento na carreira. Psico$U S F, 13,13-19$.

Magalhães, M. O. \& Gomes, W. B. (2007). Personalidades vocacionais e processos de carreira na vida adulta. Psicologia em Estudo, 12(1), 95-103.

Meyer, J. P., \& Allen, N. J. (1991). A three-component conceptualization of organizational commitment. Human Resource Management Review, 1(1), 61-89.

Mowday, R. T., Steers, R. M., \& Porter, L. W. (1979). The measurement of organizational commitment. Journal of Vocational Psychology, 14(2), 224-247.

Riveros, A. M. M. \& Tsai, T. S. (2011). Career commitment and organizational commitment in for-profit and non-profit sectors. International Journal of Emerging Sciences, 1(3), 324-340.

Rodrigues, A.C. \& Bastos, A. V. B. (2010). Problemas conceituais e empíricos na pesquisa sobre comprometimento organizacional: uma análise crítica do modelo tridimensional de J. Meyer e N. Allen. Revista Psicologia: Organizações e Trabalho, 10, 129144.

Rowe, D. E. O. \& Bastos, A. V. B. (2011). Comprometimento e Entrincheiramento na Carreira: um estudo de suas influências no esforço instrucional do docente do ensino superior. Revista de Administração Contemporânea, 15, 973-992.

Schwartz, S.H. (1992). Universals in the content and structure of values: theoretical advances and empirical test in 20 countries. In M. Zanna (Ed.), Advances in Experimental Social Psychology, (pp.1-65). Orlando: Academic.
Schwartz, S. H. (2005). Valores humanos básicos: seu contexto e estrutura intercultural. In A. Tamayo \& J. B. Porto (Eds.), Valores e comportamento nas organizações (pp. 21-55). Petrópolis: Vozes.

Schwartz, S. H. (2009). Draft Users Manual: proper use of the Schwarz Value Survey. (Resumido por R. F. Littrell). Retirado em 31 de março de 2012 do site do Centre for Cross Cultural Comparisons, New Zealand: http://www.crossculturalcentre. homestead.com.

Savickas, M. L., Briddick, W. C., \& Watkins, C. E. (2002). The relation of career maturity to personality type and social adjustment. Journal of Career Assessment, 10 (1), 24-41.

Tabachnick, B. \& Fidell, L. S. (1996). Using multivariate statistics. New York: Harper Collins.

Tamayo, A. (1994). Hierarquia de valores transculturais e brasileiros. Psicologia: Teoria e Pesquisa, 10, 269-285.

Tamayo, A. \& Porto, J. (Eds.) (2005). Valores e comportamento nas organizações. Petrópolis: Vozes.

Tamayo, A. \& Schwartz, S. H. (1993). Estrutura motivacional dos valores humanos. Psicologia: Teoria e Pesquisa, 9(2), 329348.

Tamayo, A., Souza, M., Vilar, L., Ramos, J., Albernaz, J., \& Ferreira, N. (2001). Prioridades axiológicas e comprometimento organizacional. Psicologia: Teoria e Pesquisa, 17, $27-$ 35 .
Recebido em 02/04/2012

Primeira Decisão Editorial em 12/12/2012

Aceito em 06/03/2013 